\title{
Exploring Self-Regulation of Patients with Chronic Kidney Disease Undergoing Hemodialysis
}

\author{
Belinda*1 $^{* 1}$ Zahrasari Lukita Dewi ${ }^{2}$ \\ ${ }^{1,2}$ Faculty of Psychology, Atma Jaya Catholic University of Indonesia
}

Submitted 7 November 2020 Accepted 26 January 2021 Published 30 August 2021

\begin{abstract}
Patients with chronic kidney disease (CKD) undergoing hemodialysis often experience residual impacts of the treatment on their physical, economic, social, and psychological, to an extent that CKD is considered a barrier for individuals to fully participate and enjoy life. It is crucial for CKD patients self-regulate their cognitive, social and emotional health in order to function optimally. This research aimed to explore the self-regulation process of CKD patients. This research adopted a qualitative exploratory utilizing in-depth interview as a data collection technique. There were three participants in the research recruited through convenience sampling, two men and one female aged 50-60 years and undergoing hemodialysis within 6-10 months. The analysis process used thematic analysis guided by a common-sense model of self-regulation. Findings showed that at an initial stage patients perceived CKD and its treatment emotionally, but this was changed over time to be more positive. Two participants had adequate coping strategies and received support from the closest relatives to assist in the evaluation, while, one participant was more emotionally harboring and lacked social support. The evaluation process could encourage participants to seek information and understand CKD better. Further research suggested that sampling techniques could involve participants with a more diverse age range in order to have more varied data that can be used by other CKD patients with diverse age range.
\end{abstract}

Keywords: self-regulation; chronic kidney disease; hemodialysis; common-sense model of self-regulation

Chronic ilnesse has been increasingly becoming common diseases of the global community due to the increasing number of patients and prevalence rates, estimated to reach 70\% by 2020 (Institute of Medicine of The National Academies, 2011; National Conference of Legislatures, 2012). One of most concerning type of chronic diseases in Indonesia is chronic kidney disease (CKD) (Ministry of Health of the Republic of Indonesia, 2017). In recent years, CKD has been one of the chronic diseases with the largest financing from the Indonesian Social Security Organizing Agency (BPJS) with a staggering increase of prevalence rate that reaches $13.4 \%$, which become one of the leading causes of national death rates.

CKD is caused by a disorder in the kidneys so that there is a progressive decrease in kidney function in a matter of months or years. CKD patients who is in the stage 5 of medical complication will need a replacement therapy to survive, in the form of kidney transplantation, peritoneal dialysis, and hemodialysis (Ministry of Health of the Republic of Indonesia, 2017; Setiati et al., 2014). Kidney transplantation is the ideal replacement therapy because it overcomes the consequences of all kinds of decreased kidney function, helps to achieve a better level of physical freshness, and improves the quality of life. However, the success of this transplantation takes a variety of procedures and comes with a large cost (Setiati et al., 2014). In Indonesia context, peritoneal dialysis is relatively new and patients are more common to receive hemodialysis as a therapy method. Susandijani (2018) presented that $95 \%$ of CKD patients undergoing hemodialysis. Hemodialysis treatment is routine and

${ }^{*}$ Address for correspondence: belinda.psikologi@gmail.com 


\section{Belinda \& Dewi || Exploring Self-Regulation}

lifelong. Suhardjono (in (Setiati et al., 2014) pp. 2194) explained that hemodialysis is usually done 2-3 times a week with a duration of about 4-5 hours each time of arrival. In addition, hemodialysis patients are also required to take medications and change lifestyles, such as dieting, limiting fluid consumption, and avoiding prohibited foods. Evidence showed that hemodialysis treatment affects patients' physical, economic, social, and psychological aspects. On the physical aspect, it is common for patient to experience pain in their body due to injection, muscle cramps, headaches, fatigue easily due to anemia, muscle aches, dizziness, numbness, and feelings of nausea (S. Gerogianni et al., 2014; Naderifar et al., 2017). On the social aspect, hemodialysis patients have limitations in carrying out their daily activities, of which patients should reduce or be more careful in their activities. Sexual life with spouses, and relationships with the family can also be disrupted (S. Gerogianni et al., 2014). On the economic aspect, hemodialysis patients usually are limited from being able to do formal work and have a steady income, and thus might not be able to access treatment, hemodialysis treatment and medicines (Ministry of Health of the Republic of Indonesia, 2017; Naderifar et al., 2017).

On the psychological aspect, the patients often feel negative effect on their cognition and emotion, i.e. frustration, depression, and feeling easily by disturbed with others around him (S. Gerogianni et al., 2014). Scholars such as (S. Gerogianni et al., 2014) and (S. K. Gerogianni \& Babatsikou, 2014) found that the patients experience frustration for 3-12 months due to the decreased physical and leisure ability, lifestyle change, strict diets, and routine hemodialysis treatment. Patients might also worry about death and their future, feels inhibited and dependent on others, all of which impairs their confidence. Patients who are unable to cope with the above pressures are at-risk to experience psychological disorders, such as depression, anxiety disorders, helplessness, that might lead to increased risk of suicide; lowering patient's quality of life. On the other hand, patients who are able to cope these frustrations will be able to accept the disease and adjust to the changes and limitations they have, maintaining its functions and social role (S. Gerogianni et al., 2014; S. K. Gerogianni \& Babatsikou, 2014; Revenson \& Hoyt, 2016; Yousefi \& Shahgholian, 2015).

An individual's ability to adjust to chronic disease conditions will depend heavily on his ability to regulate his thoughts, feelings, and behaviors (Solberg Nes et al., 2009). The increase in self-regulation can indirectly show a slight positive change that can affect self-care behavior and maintain chronic diseases and can improve compliance in undergoing treatment (Sauer et al., 2010; Zarmehri et al., 2018). This elaboration makes self-regulation become an important concept for patients with chronic diseases. Supported by the study by Slesnick et al. (2015) that CKD patients need attention from professionals, especially in showing obedient behavior undergoing treatment, making further research and the formation of interventions on self-regulation is crucial topic to further investigate. This study aimed to explore the self-regulation of CKD patients undergoing hemodialysis. This study adopted the Common-Sense Model (CSM) of self-regulation which emphasizes that one of the important aspects of the self-regulation process is an individual's perception of his disease (Leventhal, 2001 in (Newman et al., 2009). It is expected that findings of this study will feed evidence on designing interventions in the formation of compliant behavior undergoing treatment in CKD patients undergoing hemodialysis.

\section{Literature review}

Carver and Scheier (1981) explained that self-regulation is a dynamic system within which individuals create goals, develop strategies to achieve those goals, and assess the process and dynamic between strategies and the achievement of goals. The process is reflective and involves continuous evaluation to achieve the goals to be achieved (Carver \& Scheier, 1981) in (Vohs \& Baumeister, 2011). In the process, self-regulation involves aspects of mind, emotion, and behavior in order to achieve their goals in a fickle environment (Carver \& Scheier, 1981) in (Cameron \& Leventhal, 2003). In an everyday context, the existence of such a process can help the individual to direct the behavior shown to be in line with their goals. Whereas in the context of individuals with certain diseases, self-regulation can help individualsadjust the goals and strategies under different conditions. It is intended so that individuals are still able to show their daily function and optimal quality of life.

Meanwhile Leventhal et al. (1992) focused on the self-regulation in patients with chronic disease, known as Common-Sense Model (CSM) of self-regulation (in (Leventhal et al., 2016). In CSM theory, explained that a patient's self-regulation can be affected by perceived physical symptoms, affectiveness, and cognitive processes. The existence of CSM can show an overview of the process 


\section{Belinda \& Dewi || Exploring Self-Regulation}

passed by the patient in understanding and interpreting the disease and the way the patient develops strategies to be able to overcome and control the disease so that the patient is able to regulate every behavior that has to fit the objectives. In the context of chronic diseases, the goals to be achieved can be seen from two aspects, namely optimal physical and psychological health conditions (Cameron \& Leventhal, 2003). In the process, CSM consists of three phases: representation, coping, and reappraisal (Leventhal, 1984 in (Newman et al., 2009)). In the representation phase, the patient perceives and forms a picture of the disease as a response to the disease, both on the cognitive and emotional aspects, through information obtained based on the results of communication with others, cultural values, and perceived physical symptoms. Leventhal et al. (2016) explained that the cognitive and emotional representation of CKD patients is also known as illness perception (Jayanti et al., 2016). In the cognitive aspect, there are five variables that form the individual's representation of the disease. These are identity (the label that was given by the individual related to the disease and perceived symptoms); timeline (time of appearance, duration, fluctuations, perceptions related to the duration of the disease and the decrease that occurs, the time remaining before death); consequences (the impact experienced in the daily, social, and financial role during having the disease or following treatment); cause (the cause of the disease, such as heredity or environmental factors); and control (the individual's belief that the disease is manageable and likely to be controlled). Based on these cognitive and emotional representations, individuals will move to the coping phase, i.e. patients create and develop strategies that focus on overcoming or adjusting to the cognitive and emotional representations they have. After that, in the appraisal phase, the patient will evaluate the impact of the coping strategy that has been applied and the impact of the disease both physically and psychologically. The process will take place continuously and can change the perception that patients have regarding their disease (Broadbent et al., 2015).

\section{Self-regulation of CKD patients undergoing hemodialysis}

Self-regulation in adult individuals is a result of learning and development across lifespan period. In the learning process, there are several influential factors, namely internal factors (biological, genetic, and temperament), abilities developed with age, internal motivation (related to goals and values in the self), and external (related to punishment and reward), social support, and environmental factors (environmental conditions that can affect an individual's ability to regulate themselves). These factors will indirectly continue to affect the self-regulatory process of adults. CKD patients can represent their disease as a form of loss, threat, or challenge (Laudański et al., 2010). Such representations can be formed depending on the physical and emotional state, personality, social context, environmental circumstances, and information the patient has. This representation influences CKD patients' problem-solving strategies, of which patients have the opportunity to overcome the problems. Generally, patients who can use adaptive problem-solving strategies will be able to reduce negative emotions and change the perception formed to neutral or positive. However, patients who use maladaptive ways of solving problems are more likely to feel anxious, confused, and reject his or her condition. If the condition does not get further treatment, it will disrupt the patient's quality of life and increase the potential for the patient to be able to have psychological disorders (S. Gerogianni et al., 2014; Laudański et al., 2010) It is crucial that CKD patients are able to self-evaluate the strategies applied, both related to the success of the strategy and their physical and psychological conditions (Cameron \& Leventhal, 2003). Gradually, individuals who continuously carry out self-evaluation will be able to find adaptive problem-solving solutions and show behaviors that continue to maintain their health and well-being.

\section{Method}

\section{Participants and procedures}

This study adopted a qualitative exploratory research design. There were three research participants recruited with a convenience sampling technique, with the following criteria: male or female 


\section{Belinda \& Dewi || Exploring Self-Regulation}

\section{Figure 1}

The conceptual framework of self-regulation

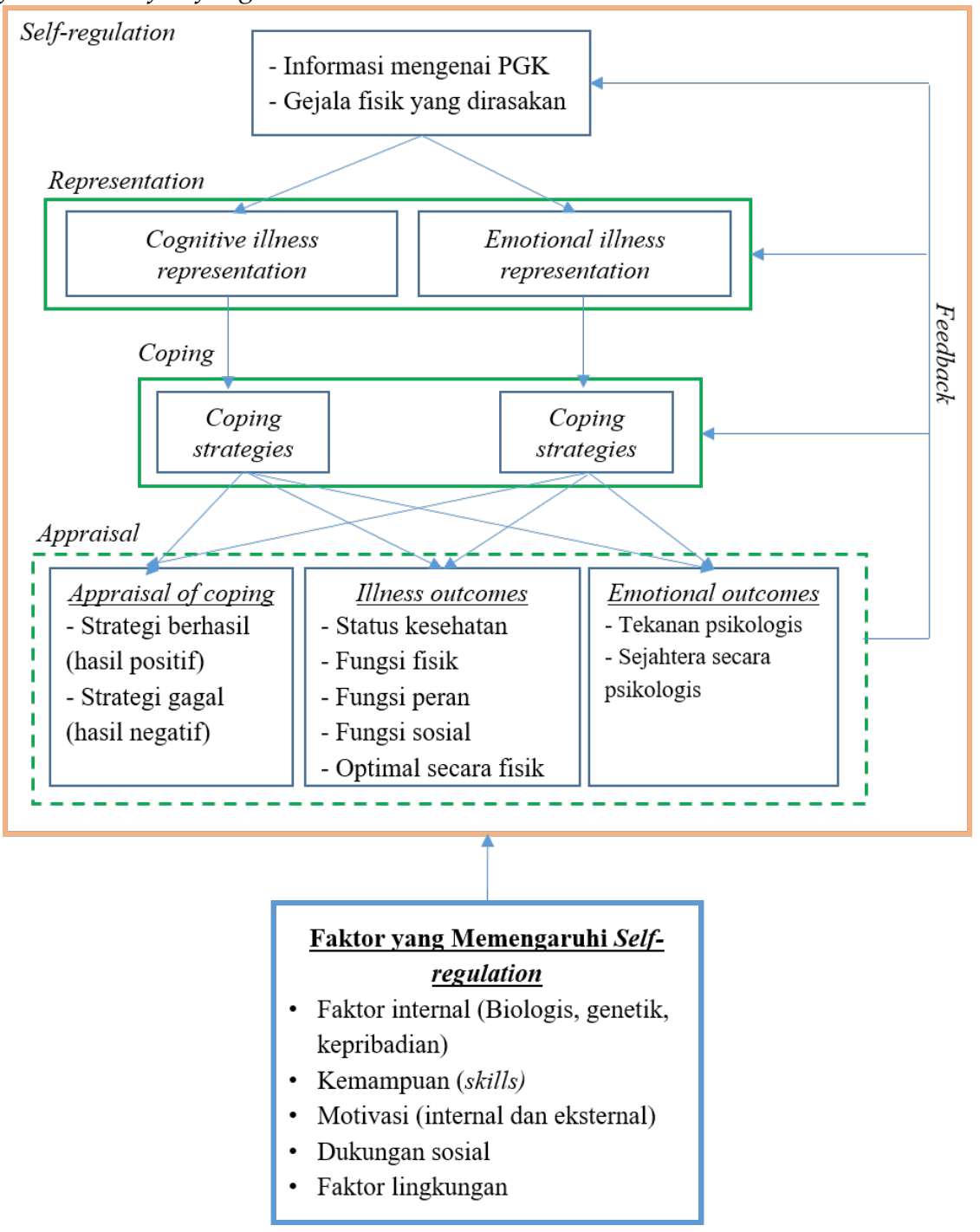

participants, in the adult age range (30 - 60 years old), and undergoing hemodialysis within a span of 3 to 12 months. Convenience sampling was used because there was a specific information that need to be collected from a certain group of people. Participants were recruited from researcher's acquitances and with the support of hemodialysis doctors. Before participating in the data collection, each participant had signed an agreement expressing their willingness to participate in this study, to fill out a questionnaire and conduct interviews for research purposes. There were three (two male and a female), aged 50-60 years, and had undergone hemodialysis within 6-10 months. Table 1 outlines the demographic of the research participants, followed by their short profile (the names of the participants have been changed for privacy and ethical reason). 
Belinda \& Dewi || Exploring Self-Regulation

Table 1

Participants Demographic Data

\begin{tabular}{|c|c|c|c|}
\hline Identity & Participant I & Participant II & Participant III \\
\hline Name & Supri & Yadi & Juli \\
\hline Gender & Male & Male & Female \\
\hline Age & 52 years old & 59 years old & 60 years old \\
\hline Employment & Employee & Entrepreneur & $\begin{array}{l}\text { Pensionary - Primary } \\
\text { School Teacher }\end{array}$ \\
\hline Address & Jakarta & Kupang & Kupang \\
\hline Medical records & - & $\begin{array}{l}\text { Diabetes, } \\
\text { hypertension }\end{array}$ & High uric acid level \\
\hline $\begin{array}{l}\text { Duration } \\
\text { hemodialysis }\end{array}$ & \pm 8 months & \pm 10 months & \pm 6 months \\
\hline Marital Status & Married & Married & Widow \\
\hline Number of children & 2 persons & 4 persons & 2 persons \\
\hline B-IPQ score & 20 & 36 & 55 \\
\hline
\end{tabular}

\section{Supri}

Supri was the head of a family with two boys, aged 17 years and 9 years. The physical symptoms of CKD that Supri felt were itching and black spots appeared on his body, chills, weakness, and shortness of breath. Since Supri was diagnosed with CKD, Supri had been treated by his wife and two children. Supri's wife decided to stop working and take care of Supri at home. His eldest son is a construction worker who has just been dismissed from work due to the Covid-19 pandemic situation. Supri admitted that he was grateful because he felt that he had received a lot of help and attention from his family, but Supri also felt sad and worried about the condition of his family who had no income. This indirectly encouraged Supri to be able to undergo regular treatment; undergoing hemodialysis, taking medication, and maintaining a diet.

\section{Yadi}

Yadi is the head of a family with four children. Three of his daughters are married and live separately from Yadi. At the time of research, Yadi lived with his wife and youngest child. Yadi's wife is a housewife who owns a food shop in front of their house, while his son was a fresh graduate seeking for a job. Before Yadi received a diagnosis of CKD, he admitted that the income from the shop was sufficient to meet the needs of his family Yadi also regularly received money from his three daughters every month, and thus family economic problems was not an issue before the diagnosis. Physical symptoms that Yadi experienced were swelling and itching in certain parts of the body, easy feelings of weakness, and shortness of breath. After receiving a diagnosis of CKD, Yadi felt very supported by his family to focus only on his health. This also motivated Yadi to maintain his physical condition so as not to sadden his wife and children.

Juli

Juli is a widow with two children who have completed their education. Juli's eldest son is already married, while his youngest is already working. One year before Juli got a diagnosis of CKD, Juli's husband passed awaybecause of an acute respiratory disease. Before Juli could accept her husband's death, Juli was diagnosed with CKD which required her to move to her eldest son's house to make it easier for Juli to undergo treatment. Juli admits that she is not very close with her eldest son and has never left the island where she lives. The fearand inability to accept her condition, made Juli feel even more depressed about her CKD. The physical symptoms that Juli experiences include itching, swelling, an easy feeling of pain in her limbs, feeling weak, and shortness of breath. 


\section{Belinda \& Dewi || Exploring Self-Regulation}

\section{Data collection}

There were two data collection instruments used in this study. Each of the instrument is outlined below:

1. A structured interview guidence.

The interview guide is made based on the CSM theory that has gone through the validation stage of an expert. Questions asked such as what information participants had regarding CKD when they got a diagnosis, what symptoms the participants felt related to the disease, what caused the participants to have the disease, what impact did participants feel due to the disease, and how did the participants feel when they got diagnosed CKD?

2. description Brief-Illness Perception Questionaire (B-IPQ).

One of the instruments often used to measure the perceptions of chronic disease patients is the Brief-Illness Perception Questionaire (B-IPQ) which was developed based on the CSM theory. The B-IPQ consists of nine items that measure cognitive and emotional perceptions. A high score indicates that the individual views the disease as threatening or negative. High scores can be associated with poor psychological, social, physical, and health conditions (Strauman, 2017).If the score is classified as low, the individual perceives the disease as something that is not dangerous or tends to be positive.

\section{Data analysis}

The data obtained consisted of quantitative data obtained from the B-IPQ score and qualitative data obtained from interviews. However, this study focused more on qualitative data, while quantitative data was used to classify the three participants' perceptions of disease, namely high, medium and low. With this classification, the process that the three participants will go through will become clearer. The analysis was carried out using the thematic analysis method, which is the process of coding information that can produce a list of themes, models, and qualifications related to that theme (Poerwandari, 2013). The themes used are inductive process that is consist of the representation phase (identity, cause, consequence, control, timeline, and emotional illness representation), the coping phase, and the appraisal phase. The qualitative data obtained has gone through a validity process in the form of argumentative and communicative validity. In addition, the data credibility method used is in the form of data triangulation involving caretakers of the three participants.

\section{Findings}

\section{$B-I P Q$ score}

Juli had the highest B-IPQ score of the other two and indicated the most negative representation of disease and a condition more prone to psychological disorders than the other two participants. This is different from the situation of the other two participants whose perceptions tend to be more positive. In addition, another thing that can affect the perception of the disease was the history of the disease. In Juli's case, her history of gout caused her to feel more severe pain than the other two participants, so that the condition prevented Juli from carrying out her daily activities. When linked to the self-regulatory process, initially the three participants represented CKD as a frightening and life-threatening disease. However, the representations of Supri and Yadi's disease changed to be more positive along with the implementation of appropriate coping strategies and evaluations. The coping strategies carried out by Supri and Yadi are divided into coping strategies that focus on overcoming the problems they have (problem-focused) and emotions that are felt (emotional-focused). The coping strategies used to overcome the problems they have were in the form of seeking support and assistance from other people and undergoing regular treatment, while the coping strategy to overcome the emotional reaction is in the form of increasing worship. In addition, Supri and Yadi often get input from their families if there are actions that were mistakes in their actions, and they were able to accept that input. This is different from Juli, who harbored stronger emotions and did not carry out evaluations, and thus she still had the same perception when she first got the diagnosis of CKD. 


\section{Belinda \& Dewi || Exploring Self-Regulation}

\section{Representation phase}

Initially, the three participants did not have information related to their disease. The three participants slowly developed their knowledge after receiving a diagnosis of CKD. This information comes from talking with medical professionals such as doctors and nurses, discussion with the closest people such as family, discussion with the surrounding environment, such as neighbors. Apart from other people, the three participants also received information about their physical condition based on their physical symptoms and their own experiences.

\section{Cognitive illness representation}

In general, the three participants have a similar representation of the identity, cause, and consequences variables, while in the timeline and control variables, the three participants show different representations.

\section{Identity}

The three participants were aware of changes in their physical conditions before getting a diagnosis. Physical symptoms that they experienced include itching, swelling, and body aches, weakness, shortness of breath, and chills. The three new participants were able to label this physical condition as a symptom of CKD after being treated at the hospital. Apart from the initial symptoms, other physical symptoms such as when the hemoglobin level drops and while undergoing hemodialysis, are also labeled as symptoms of CKD.

"... In the afternoon, I want to go to the doctor, in the morning I feel weak and out of breath. Taken to the hospital by his wife, he said that HB went down ... If I cough and drink too much, then I will be out of breath. So, If I out of breath, I usually take medicine immediately... " (Supri, 2020).

"Initially, the legs, face, stomach were all swollen. Then the body all itches too ... My wife said that if my $H B$ went down, I would be furious. After the rage, I didn't realize myself... " (Yadi, 2020).

"... So back then, my feet were swollen and the body was itchy. First I think it's because of uric acid. So I just let it go ... But it didn't heal, the leg was still swollen. Then I was itching on all of my body... Yes, I am healthier, I am happier now. This leg is not swollen, it doesn't hurt anymore. The itching has also disappeared because of continued dialysis, taking medication..." (Juli, 2020).

\section{Cause}

The three participants assumed that their disease was caused by their diet. Two participants who had history of the disease also considered their previous disease as one of the factors that caused both of them to have CKD, as espoused below:

"...my wife who said don't drink this or that. Peoples are told my wife that I should not drink extra joss often, or I will get kidney problems. Then the people in the warung also report to my wife that I buy extra joss, and always told her that I will have a kidney problem if I didn't fix my drinking habit. When I went to the doctor, the doctor also asked, if I like drinking soda, it's extra joss..." (Supri, 2020)

"... The doctor said that I had this kidney because of diabetes and hypertension. My child is also looking for it on the internet too, he said because I didn't take care of eating ... I used to smoke too, I smoked a lot... But that's what I was really confused about, when I was young I liked sports, why did I get kidney disease..." (Yadi, 2020)

"... After that, the doctor told me that kidney disease could be due to uric acid, not drinking enough, and a high level of sugar. I said that I was not taking care of eating, so the doctor said that can be one of the causes that I have a kidney problem ..." (Juli, 2020)

\section{Consequence}

The impact felt by the three participants was a physical condition that was disturbing and very limiting, making them bound to undergo treatment and difficulty in carrying out activities. In addition, their CKD made the three participants more irritable, which affected their relationships with their families. 


\section{Belinda \& Dewi || Exploring Self-Regulation}

"... I feel limp every day, can't work, can't do anything... Yes, I think about my work, my family can eat or not. If I don't work, what do I get for the money... The change is, now I can't work hard. Must be balanced with the disease. No weight lifting..." (Supri, 2020).

"... The change is, if I used to smoke, now I don't. Closer to children, because they don't work and me too, so we spend a lot of time at home, more diligent in praying too. My feelings have changed a lot too..." (Yadi, 2020).

"... When I live here, I can't do anything, remembering my husband all of the time... I have to watch overeating, I can't eat everything I want. Only a little. Because of this illness, it's hard to go back to Rote... It frightens me because there have never been such operations... every dialysis is initiated with injection, then dialysis. It hurts when you get an injection. I was afraid that if I wanted dialysis, so often I didn't want to do dialysis..." (Juli, 2020).

\section{Timeline}

Yadi and Juli perceived CKD as an incurable disease that lasts a lifetime. That is in contrast to Supri who still had hope and confidence that the disease can be cured soon.

“... Now, I am feeling healthier because of listening to my wife... Now I am also not tired, I am more refreshed ... The medicine has also decreased. It used to be up to 7-8 drugs. Now, there are only 4 types of medicine left ... This was checked by the doctor, everything is normal. This is a damaged kidney. Alhamdulillah, $80 \%$ of the normal, doctor said. If the heart is healed. If the kidneys are $85 \%$ good, the doctor said. Yes, it can be cured, said the doctor..." (Supri, 2020).

"... The swelling and itching are no longer... If the weakness is occasional, but usually I ask the child to have a massage ... The doctor said I have to continue to take care of eating, take care of drinking, that's also dialysis so it's not like it used to be anymore. But I thought how long I had to be like this?" (Yadi, 2020).

"... I cannot do anything, I am afraid that people say it cannot be cured, many people died because of dialysis ..." (Juli, 2020).

\section{Control}

Supri and Yadi considered that both of them had great control over their disease, namely by undergoing hemodialysis, taking medication, limiting fluid consumption, and maintaining a diet, in contrast to Juli who felt that she was helpless to be able to control her disease.

"I don't think that the medicine I consume has any effect. I am just tired after taking the medicine So sometimes I don't want to take medicine, but my wife tells me to keep it from dropping, not to be treated in the hospital anymore..." (Supri, 2020).

"... Yes, it can be cured. You need to take care of eating, drinking. Routine to do the dialysis. But the most important thing is to take care of eating and drinking... But I heard my friend said that taking herbal medicine can heal. Many who took herbal medicine recovered... " (Yadi, 2020).

“... Do nothing. Just pray, ask God to heal this pain, so I can be healthy again. I pray every day, ask God to take this pain. Only God can cure disease, so I ask to cure this disease. When I am on dialysis, I pray that my dialysis will run smoothly, so that I can get better soon... " (Juli, 2020).

\section{Emotional illness representation At first}

the three participants felt scared and helpless by the diagnosis of CKD and represented CKD as frightening and threatening to their survival. However, Supri and Yadi were able to overcome their emotions so that they were able to change the representation of their illness to be more positive. In contrast to Juli, who was still very much influenced by her negative emotions, so she still felt helpless and saw her illness as a frightening thing.

"... at first, I was sad, but I can't do anything. that was my fault, also being naughty even though I was told by my wife, I can't do anything .... I just accept it, this is given by Allah. Alhamdulillah, if I was given health, so I also accept the disease as it is. It cannot be rejected, who is given a fortune like this, yes I accept it, it cannot be rejected, the name is also a disease..." (Supri, 2020). 


\section{Belinda \& Dewi || Exploring Self-Regulation}

"... Before that, I couldn't think anymore. Initially, I was afraid because I heard that many dialysis people died a lot. But when the doctor said I had to dialysis, okay, I accepted it, just let me do it... Now, I feel happier. In the past, I used to be in and out of the hospital. In the past, I was hospitalized twice a week..." (Yadi, 2020).

"... At first, I was sad, scared, I cried. Recently my husband passed away, now I am also sick and can't do anything... That frightens me because there have never been any operations like that. In those early months, if I want dialysis, the nurse will put the machine on my chest. Every dialysis is initiated by injection, then dialysis. It hurts when I get an injection... I rarely go to the hospital. Listen it must be surgery and got injected scared me...." (Juli, 2020).

Coping Phase

The three participants showed different ways of dealing with CKD, both in overcoming problems (problem-focused coping) and expressing emotions (emotional-focused coping). In overcoming the problems that arise from CKD, Supri and Yadi are trying to find more information about CKD, undergo regular treatment, and seek support from others. In contrast to July, who chose to save her problems. Meanwhile, in dealing with emotions, Supri and Yadi tried to express their emotions by telling others and praying. In contrast to July, who prefers to bury her feelings.

"When I was single, I took care of everything myself, kept it myself, thought about it myself. After marriage, my wife always asks me if something happens and she asks me to talk with her. If not, it will affect my blood tension. I need to keep my blook tension, not high. So that my wife doesn't get frustrated too ... Yes, we are get closer with God, pray diligently, give thanks, ask for forgiveness, ask to get well soon like before... " (Supri, 2020).

"... I couldn't think of anything anymore. So that day I called all of my family, the family gathering... Yes, don't think about it. Don't think too much. So, at night, now we quickly go to sleep, at 7 or 8 it's already asleep. So there is no such thought... Usually, when I am doing dialysis, I will be praying, hopefully, it will run smoothly. Previously, if I wanted dialysis, I was worried, so I kept praying. The doctor also said that we must pray, so that nothing happens. So yes now it's normal. No need to worry anymore..." (Yadi, 2020).

"... I am a layman, so I don't know what to eat. The child asked the doctor, asked the nurse, he said that I could not eat this, I could not eat that, I could not eat many foods. It's hard, I want to eat this, I can't. So sometimes I still did not take care of my eating behavior... If in the past I used to talk to my husband, then he was told what I should be like. But now, my husband had gone, no one told me what I should be like. So I keep it to myself. Don't know whom to tell..." (Juli, 2020).

\section{Appraisal Phase}

Supri and Yadi evaluated their coping strategies, both in dealing with problems they had and expressing emotions. This has an impact on changing the goals to be achieved and the strategies used. At first, Supri and Yadi received a warning and input from their family. Supported by being open to receiving input, Supri and Yadi tried to recognize their mistakes and change their behavior. This condition is different from July, who has not yet determined the goals to be achieved after receiving a diagnosis of CKD. Juli also did not receive input and support from her eldest son. This directly hampered the evaluation process which July went through.

The evaluation process carried out by the three participants did not only come from themselves but also was assisted by monitoring from their families and doctors. Self-evaluation is carried out based on the changes felt in the physical, emotional, and ability to carry out activities. Meanwhile, families and doctors conducted an evaluation based on the physical conditions shown by the three participants.

"... she gave me the medicine, she told me that the doctor's advice must be accepted, the medicine must be consumed keep your diet, don't eat it, don't eat lots of water, that's drinking $600 \mathrm{ml}$ a day. Yes, slowly understand now ... Yes, I said something but it's not clear, like babbling. She always asks me to said it clearly so people know what I mean, don't talk about what's unclear. Sometimes it makes me angry with her, which makes my sons gets angry too..." (Supri, 2020).

"... Especially in Kupang when it's dry, it's really hot. The last dry season in Kupang was very hot, so the doctor said that many dialysis patients died because of too much water. Then in Kupang, it is also 


\section{Belinda \& Dewi || Exploring Self-Regulation}

difficult to control your eating behavior. We always have a party and when you had a party, there always had meat, alcohol, wine. So yes, my wife must be taken care of at all..." (Yadi, 2020).

"... Initially, I wanted to try, but now I feel healthier, afraid I will go weak like that again. Now also take care of eating, eat less meat, the doctor said you shouldn't eat, don't eat. Routinely do the dialysis, followed the doctor's words. I was scared but I need forced myself to do it to be healthy..." (Juli, 2020).

Factors in self-regulation

Among the three participants, Supri's CKD is very impactful to his family. His wife is the only person who cares for Supri and the four themes also appear as the wife's complaint. This unpleasant experience made Supri's wife feel frustrated with the medication and diet that Mr. Supri had to endure, tired of additional responsibilities as a nurse, and feeling worried about Supri's condition and the possibility of having a disease similar to Supri's. In contrast to the child from July who was not actively involved in the treatment that was undertaken by Juli. In Juli's case, the unpleasant experience her son had was the increased responsibility for caring for his mother while living in the same house. Regardless, Juli's child chose to ignore him. Based on the unpleasant experiences experienced by these families, it can be seen that families who actively take care of CKD patients also need support from other people and professionals, both in dealing with CKD patients and in managing themselves while caring for CKD patients.

“... From myself, I need to keep my spirit, accept good advice from other people. He said you would get well. Alhamdulilah, I accept ... It's the same now that my parents are gone, distant relatives, I'm worried about my wife and children. Now, I realize that I need to keep my spirit because I have a wife and children. Struggling to get rid of my illness for my wife and children..." (Supri, 2020).

"... So that day I contacted all of my family, the family gathering ... I asked the doctor a lot about it, whether to eat this or not. Before dialysis, I also asked the doctor a lot, what was dialysis like, why did I have this kidney, I asked a lot about it...." (Yadi, 2020).

“... But now, my husband had gone, I also stopped teaching. So I keep it to myself. Don't know whom to tell ... Then the child gets angry, quarreling just because of my eating behavior. She said I like to get angry easily. If we have had a fight, she usually just stay quiet in the room or leave. I don't know anyone in Kupang, so only can stay at home... "(Juli, 2020).

\section{An overview of the self-regulatory process}

In general, the disease representations of the three participants showed a change at the time of initial diagnosis and at the time of the interview. These changes can occur because of the evaluation process carried out by the three participants, so that it can indirectly increase the information that participants have, both regarding CKD and regarding coping strategies that can be carried out in dealing with problems that arise due to illness and overcoming their emotions.

For the three participants, the evaluation process began when participants felt a difference in their physical condition after undergoing treatment for a certain time. If it is related to the participant's experience, these changes begin to appear when there is a change in the hemodialysis method, namely from flowing blood directly to the heart being transferred to the hands. The change in their physical condition made participants begin to realize the effectiveness and importance of undergoing treatment. This awareness can further encourage participants to be able to proceed with the treatment. Based on this, it can be seen that the behavior of undergoing treatment is an important starting point for CKD patients. When CKD patients already feel positive changes in their physical condition, CKD patients will be able to have a more positive representation of their disease, both in cognitive and emotional aspects, so that it can also lead to more optimal physical and psychological conditions. 


\section{Belinda \& Dewi || Exploring Self-Regulation}

\section{Discussion}

The findings in this study indicate that in general the self-regulatory process that CKD patients go through is not only fixated on the individual, but also the contribution of various other factors outside the individual, both in gathering information about CKD, finding appropriate and adaptive coping strategies and in conducting an evaluation, the patient also still needs monitoring from other people.

In the process, CKD patients face various problems, both in dealing with the disease and undergoing treatment recommended by medical professionals. The problems referred to include physical, emotional, psychological, economic, and occupational aspects, as well as the rules for maintaining a diet. Jarial and George (2017) also found a similar problem in their research. However, what is different is that there are no problems in establishing relationships and communicating with medical professionals, such as doctors and nurses. In this study, the three participants considered medical personnel as reliable experts and sources of information about CKD. The difference in perceptions made the relationship between the three participants and medical personnel a supporting factor, not a problem, and a factor that hindered the process of self-regulation.

The existence of a figure who is considered an expert also indirectly affects the coping strategy that is carried out. Ghaffari et al. (2019) found that hemodialysis patients show more effort to overcome negative emotions they have due to their illness. This is different from the findings in the present study, where the three participants focused more on overcoming problems that arise due to the CKD they have. This might be because the three participants have received all the information about CKD from medical personnel so that participants can immediately apply the instructions from medical personnel. This is in line with the research results of Griva et al. (2020) that the solution is obtained from medical professionals who are trusted and considered experts. In contrast to coping strategies in dealing with their emotions, the three participants did not receive information related to this, so that participants tended to have difficulty coping with their emotions.

For patients who were unable to cope with their emotions, they continued to have emotional distress. In addition, participants who had that the solution is obtained from medical professionals who are trusted and considered as experts. In contrast to coping strategies in dealing with their emotions, the three participants did not receive information related to this, so that participants tended to have difficulty coping with their emotions.difficulty coping with feelings of fear and anxiety, both related to illness and treatment, also showed behavior not adhering to treatment. This is in line with the research results of Suganthi et al. (2020) that the high emotional pressure hemodialysis patients have can be caused by low adherence to treatment. Gillanders et al. (2008) also found that the ability to regulate emotions will affect well-being and the ability to control disease that an individual has.

Although the three participants had solutions to overcome physical symptoms and diseases they had, the experience of receiving a diagnosis and undergoing the recommended treatment remained an unpleasant and difficult experience to live with. In this study, it was found that participants who suddenly received a diagnosis of CKD showed a more accepting attitude and could more easily undergo the recommended treatment. This might happen because of the assumption that he would be able to recover immediately if he takes the recommended treatment. In contrast to participants who had a previous history of the disease, they tended to feel anxious about what they had done related to previous illnesses so they could have CKD. This is in line with the results of the research conducted by S. K. Gerogianni and Babatsikou (2014), which stated that the things experienced by these participants are normal for CKD patients because when they are diagnosed for the first time, CKD patients will enter a honeymoon period, which is the first 1-3 months.

After undergoing the honeymoon period, the patient will face a frustrating period that takes 3-12 months (S. Gerogianni et al., 2014). In line with this explanation, the researchers found that the first three to four months after getting a diagnosis was the most difficult period for hemodialysis patients because during that time they still felt disturbed by their physical symptoms even though they had undergone the recommended treatment. However, after starting to feel positive changes in their physical condition and undergoing different hemodialysis procedures, the frustration of the three participants gradually diminished. Based on this, it can be seen that the label is given to CKD patients really depends on the treatment they are taking (Karamanidou et al., 2014). Besides that, when patient's physical symptoms begin to subside, they tend to perceive their illness more positively. This 


\section{Belinda \& Dewi || Exploring Self-Regulation}

is in line with the results of the study by Pagels et al. (2015) that CKD patients who have few symptoms will have a more positive perception. Based on this, the disease history of CKD patients can be further considered for further research.

However, this does not mean that after overcoming this, the frustration that CKD patients have will disappear. This is because in this study it was found that after participants were able to adjust to their physical condition and were able to demonstrate the behavior of undergoing treatment regularly, participants would begin to feel bored with treatment and a desire to try other treatments that were considered more promising, such as herbal medicine. This is in line with findings from Griva et al. (2020) study that traditional medicine is often used as a treatment option that is more trusted by patients because of the public's belief about its success. Thus, it can be seen that the problems of CKD patients cannot be resolved immediately by showing adherence to treatment behavior, but it also requires a long-term commitment to maintaining this behavior. If the CKD patient is unable to overcome the the boredom, then this can turn into a risk factor that can interfere with the physical condition of the CKD patient.

Subramanian et al. (2017) found that coping strategies are strongly influenced by various factors, such as interpretation of treatment, time of diagnosis, disease history, and the meaning of self-limitation. The existence of these factors makes various types of coping strategies that can be demonstrated by hemodialysis patients, both actively and passively. Each coping strategy undertaken by an individual will affect the pressure and expectations the patient has regarding the disease they have (Gao et al., 2016). The researcher also found that participants who were unable to cope with the pressure that arose from their illness showed themselves as helpless individuals and had no hope of recovery.

In general, Bauer and Baumeister (Vohs \& Baumeister, 2011) explained that individual self-regulation can be influenced by various things, one of which is culture. In this study, the cultural aspect did not directly affect individual perceptions in viewing their disease, but rather in shaping the female personality. Hidajat (Nurrachman \& Bachtiar, 2011) explained that in Eastern culture, women are required to conform to relationships, act appropriately, and strive to fulfill duties, obligations, and social responsibility. With these demands, women tend to obey and follow the social codes. This is in line with the findings of researchers regarding the female participants who were involved. The circulating social values instate that the main obligation of women is to marry and follow their husbands, made the participants mold themselves as individuals who follow and adapt to their environment, and there was no encouragement to do other things. Based on this explanation, the researcher considers that personal formation due to culture also indirectly affects the self-regulation that is undertaken by individuals.

In the process of self-regulation carried out by hemodialysis patients, individuals will perceive the disease they have, both cognitively and emotionally, based on the information and physical symptoms they feel. In this study, researchers found that in female patients, feelings of physical pain due to injections before undergoing hemodialysis also affected their emotional representation. This is also supported by the high B-IPQ score they had, especially in the emotional aspect. Based on these representations, individuals will show efforts to overcome these perceptions.

In dealing with CKD, patients need other people. However, this support is not only needed by the patient, but also by the patient's family. This is in line with the explanation of DePasquale et al. (2019) that there are four main themes related to unexpected and unpleasant experiences experienced by families of CKD patients, namely: being a partner caring for patients, responding to psychological conditions, patients convey matters related to treatment and the condition of vulnerable patients. If associated with this study, these four themes were also experienced in the families of the participants, and this experience will increase in its intensity and have an impact on families who are actively involved in caring for and accompanying CKD patients.

Apart from being based on the research findings, other things that can also be discussed in this study are the limitations and weaknesses that the researchers found. The pandemic situation and limited time, caused this study have very limited participant access and data collection. In addition, this study also did not include more comprhensive information provided by health professionals and a history of other diseases, as well as the services provided to the three participants from the hospital. The existence of limitations and weaknesses in this study is expected to be used as input for further 


\section{Belinda \& Dewi || Exploring Self-Regulation}

research.

\section{Conclusion}

The study showed steady changes in cognitive and emotional representations about chronic kidney disease among the patients' self-regulation process. These changes occured because of the evaluation and feedback process carried out by the participants, of which add participant information, both about CKD and coping strategies that can be carried out. Having more information will help CKD patients form a positive representation of their disease. Participants initially represented CKD emotionally as scary and negative. However, this representation changes along with the coping and evaluation strategies. After obtaining more information about CKD, new participants will begin to represent the disease cognitively. The three participants showed a similarity in the identity variable (physical symptoms that they feel are labeled as symptoms of CKD they have), cause (the cause of CKD is due to diet) and the consequences (the perceived impact are physical limitations and dependence on medication that makes participants have difficulty in undergoing activities).

In the coping phase, the three participants demonstrated coping strategies that focus on solving their health problems, namely by undergoing treatment. Meanwhile, in coping with their emotions, only two participants showed adaptive coping strategies. In the evaluation phase, the process carried out by the three participants came from themselves and was assisted by supervision from others. However, the three participants showed differences related to what was evaluated; in coping strategies, physical and psychological conditions. The supporting factors for self-regulation consist of adequate ability to set goals and develop strategies, internal and external motivation, and social support from health workers and families. Constraining factors are internal factors (health and personality conditions) and environmental factors, depending on the meaning and conditions faced by each CKD patient.

\section{Recommendation}

The findings in this study can be used as a basis to develop interventions in increasing adherence to treatment behavior in CKD patients undergoing hemodialysis. There are several suggestions that can be given for further research. First, there needs to be an evaluation of the sampling technique used so that it can provide a more comprehensive picture. Second, the issue of CKD will be influenced by patient's developmental stageso that further studies of CKD patients of different age ranges will support the formation of more appropriate interventions. Third, future studies can consider the history of the disease as something that can affect the self-regulation of CKD patients, so that this can be taken into consideration in future studies.

Last, the sampling technique used in this study is convenience sampling or a sampling technique that only involves available participants, which makes this study only able to provide an overview of self-regulation in late adult CKD patients. Future studies are expected to use a sampling technique in the form of purposive sampling so that the participants involved can come from a more diverse range of adult ages and can provide a more comprehensive picture of self-regulation in adult CKD patients undergoing hemodialysis. In addition, the investigators also found that participants without a prior history of disease had a more positive representation of the disease than participants with a history of the disease. Based on this, further research may consider determining the characteristics of the participants based on their medical history.

\section{Acknowledgments}

Thanks to the participants who were involved in this research, to dr. Maria Michaela St. Rea and dr. Hanny as a hemodialysis doctor who has helped researchers to meet and collect data with participants, as well as to the lecturers who have guided during the research writing process.

\section{Authors' contributions}

First author developed a research concept, collected data, and wrote the research paper. The second author assisted in writing discussion, conclusion, and implication, and supervised the writing process. 


\section{Belinda \& Dewi || Exploring Self-Regulation}

\section{Conflic of Interest}

The researchers stated that there was no conflict of interest in this study.

Orcid Id

Belinda 0000-0002-8438-9388

Zahrasari Lukita Dewi 0000-0002-2992-6742

\section{References}

Broadbent, E., Wilkes, C., Koschwanez, H., Weinman, J., Norton, S., \& Petrie, K. J. (2015). A systematic review and meta-analysis of the Brief Illness Perception Questionnaire. Psychology and Health, 30(11). https://doi.org/10.1080/08870446.2015.1070851

Cameron, L. D., \& Leventhal, H. (2003). The self-regulation of health and illness behavior. Routledge.

Carver, C., \& Scheier, M. (1981). The self-regulation of health and illness behavior. New York, Springer Verlag.

DePasquale, N., Cabacungan, A., Ephraim, P. L., Lewis-Boyér, L., Powe, N. R., \& Boulware, L. E. (2019). Family members' experiences with dialysis and kidney transplantation. Kidney Medicine, 1(4), 171-179. https://doi.org/10.1016/j.xkme.2019.06.001

Gao, Y., Zhou, Y., Guo, C.-X., \& Zhao, J.-F. (2016). The relationship among hope, symptom distress, social support, coping style and monthly income in maintenance hemodialysis patients: A structural equation model, 9, 19717-19724.

Gerogianni, S., Babatsikou, F., Gerogianni, G., Grapsa, E., Vasilopoulos, G., Zyga, S., \& Koutis, C. (2014). Concerns of patients on dialysis: A research study. Health Science Journal, 8(4), 423-437.

Gerogianni, S. K., \& Babatsikou, F. P. (2014). Psychological aspects in chronic renal failure. Health Science Journal, 8(2), 205-214.

Ghaffari, M., Morowatisharifabad, M. A., Mehrabi, Y., Zare, S., Askari, J., \& Alizadeh, S. (2019). What are the hemodialysis patientsśtyle in coping with stress? A directed content analysis. International Journal of Community Based Nursing and Midwifery, 7(4). https: / / doi . org / 10. 30476/IJCBNM.2019.81324.0

Gillanders, S., Wild, M., Deighan, C., \& Gillanders, D. (2008). Emotion regulation, affect, psychosocial functioning, and well-being in hemodialysis patients. American Journal of Kidney Diseases, 51(4). https://doi.org/10.1053/j.ajkd.2007.12.023

Griva, K., Seow, P. S., Seow, T. Y. Y., Goh, Z. S., Choo, J. C. J., Foo, M., \& N, S. (2020). Patient-related barriers to timely dialysis access preparation: A qualitative study of the perspectives of patients, family members, and health care providers. Kidney Medicine, 2(1), 29-41. https: / / doi.org/10.1016/j.xkme.2019.10.011

Institute of Medicine of The National Academies. (2011). Living well with chronic illness: A call for public health action. National Academies Press. https://doi.org/10.17226/13272

Jarial, S., \& George, R. M. (2017). Lived experience of patients undergoing hemodialysis. Journal of Medical Surgical Nursing Practice and Research, 1(1), 17-23. https: / / doi.org/10.21474/ijar01/ 3962

Jayanti, A., Foden, P., Wearden, A., \& Mitra, S. (2016). Illness beliefs in end stage renal disease and associations with self-care modality choice. PLOS ONE, 11(7). https: / / doi .org / 10.1371 / journal.pone.0154299

Karamanidou, C., Weinman, J., \& Horne, R. (2014). A qualitative study of treatment burden among haemodialysis recipients. Journal of Health Psychology, 19(4). https : / / doi . org / 10.1177 / 1359105313475898

Laudański, K., Nowak, Z., \& Wańkowicz, Z. (2010). Psychological aspects of dialysis: Does cognitive appraisal determine the overall outcome? https:// doi.org/10.20452/pamw.881

Leventhal, H., Alison Phillips, L., \& Burns, E. (2016). Modelling management of chronic illness in everyday life: A common-sense approach. Psychological Topics, 25(1), 1-18. 
Leventhal, H., Diefenbach, M., \& Leventhal, E. A. (1992). Illness cognition: Using common sense to understand treatment adherence and affect cognition interactions. Cognitive Therapy and Research, 16(2), 143-163. https:/ /doi.org/10.1007/bf01173486

Ministry of Health of the Republic of Indonesia. (2017). Situasi penyakit ginjal kronis. [The situation of chronic kidney disease]. www.depkes.go.id/resources/download/pusdatin/infodatin/

Naderifar, M., Tafreshi, M. Z., Ilkhani, M., \& Kavousi, A. (2017). The outcomes of stress exposure in hemodialysis patients. Journal of Renal Injury Prevention, 6(4). https:/ / doi.org/10.15171/jrip. 2017.52

National Conference of Legislatures. (2012). Chronic disease prevention and management strategy chronic disease prevention and management. Maryland, Health Resources; Services Administration.

Newman, S., Steed, L., \& Mulligan, K. (2009). Chronic physical illness: Self-management and behavioral intervention.

Nurrachman, N., \& Bachtiar, I. (2011). Psikologi perempuan: Pendekatan kontekstual Indonesia [Woman's psychology: The Indonesian contextual approach]. Universitas Atma Jaya.

Pagels, A. A., Soderquist, B. K., \& Heiwe, S. (2015). Differences in illness representations in patients with chronic kidney disease. Journal of Renal Care, 41(3). https://doi.org/10.1111/jorc.12117

Poerwandari, K. (2013). Pendekatan kualitatif untuk penelitian perilaku manusia [Qualitative approach for research in human behavior]. Depok, LPSP3 UI.

Revenson, T. A., \& Hoyt, M. A. (2016). Chronic Illness and Mental Health. In Encyclopedia of mental health: Second edition. https:/ / doi.org/10.1016/B978-0-12-397045-9.00151-8

Sauer, S. E., Burris, J. L., \& Carlson, C. R. (2010). New directions in the management of chronic pain: Self-regulation theory as a model for integrative clinical psychology practice. Clinical Psychology Review, 30(6), 805-814. https://doi.org/10.1016/j.cpr.2010.06.008

Setiati, S., Alwi, I., Sundoyo, A. W., Simadibrata, M., Setiyohadi, B., \& Syam, A. F. (2014). Buku ajar: Ilmu penyakit dalam ed. 6. [Course book: The science of internal diseases, 6th ed.]

Slesnick, N., Pienkos, S., Sun, S., Doss-McQuitty, S., \& Schiller, B. (2015). The chronic disease self-management program-A pilot study in patients undergoing hemodialysis. Nephrol News, 29(4).

Solberg Nes, L., Roach, A. R., \& Segerstrom, S. C. (2009). Executive functions, self-regulation, and chronic pain: A review. Annals of Behavioral Medicine, 37(2), 173-183. https: / / doi .org / 10. 1007/s12160-009-9096-5

Strauman, T. J. (2017). Self-regulation and psychopathology: Toward an integrative translational research paradigm. Annual Review of Clinical Psychology, 13. https:/ /doi.org/10.1146/annurevclinpsy-032816-045012

Subramanian, L., Quinn, M., Zhao, J., Lachance, L., Zee, J., \& Tentori, F. (2017). Coping with kidney disease - qualitative findings from the Empowering Patients on Choices for Renal Replacement Therapy (EPOCH-RRT) study. BMC Nephrology, 18(1). https: / / doi.org/10.1186/s12882-0170542-5

Suganthi, S., Porkodi, A., \& Geetha, P. (2020). Assess the illness perception and treatment adherence among patients with end-stage renal disease. Iranian Journal of Nursing and Midwifery Research, 25(1). https://doi.org/10.4103/ijnmr.IJNMR_74_19

Susandijani. (2018). Solusi terapi penderita gagal ginjal? cek plus minusnya [therapy solutions for kidney failure patient? check the pros and cons]. https://gaya.tempo.co/read/1147254/capdsolusi-terapi-penderita-gagal-ginjal-cek-plus-minusnya?page_num $=2$

Vohs, K. D., \& Baumeister, R. (2011). Handbook of self-regulation 2nd ed. The Guilford Press.

Yousefi, H., \& Shahgholian, N. (2015). Supporting hemodialysis patients: A phenomenological study. Iranian Journal of Nursing and Midwifery Research, 20(5). https: / / doi.org/10.4103 /1735-9066. 164514

Zarmehri, N. S., Hassanzadeh, F., Aghebati, N., \& Sharifipour, F. (2018). Comparison of the effects of using self-regulation theory and self-care education on medical adherence in patients receiving peritoneal kidney dialysis. Evidence Based Care Journal, 8(3). https: / doi.org / 10.22038 / ebcj. 2018.29148.1723 